\title{
Cancer incidence and mortality around the Pan Britannica Industries pesticide factory, Waltham Abbey
}

P Wilkinson, B Thakrar, G Shaddick, S Stevenson, S Pattenden, M Landon, C Grundy, P Elliott

\begin{abstract}
Objectives-To examine the incidence and mortality of cancer near the Pan Britannica Industries factory, Waltham Abbey, after reports of a possible cluster of all cancers and brain cancer in the vicinity.

Method-Small area study of cancer incidence 1977-89, and mortality 1981-92, within a $7 \cdot 5 \mathrm{~km}$ radius of the factory site. Postcoded cancer registrations and deaths in the study area were extracted from national data sets held by the Small Area Health Statistics Unit and compared with expected numbers computed by applying national rates stratified for age, sex, and deprivation to the local population (1981 and 1991 censuses). Observed/ expected $(\mathrm{O} / \mathrm{E})$ ratios were examined from $0-1 \mathrm{~km}$ and $0-7.5 \mathrm{~km}$ of the plant, and tests applied for a decline in relative risk with distance up to $7 \cdot 5 \mathrm{~km}$.
\end{abstract}

Results-There were 12859 incident cancers (1977-89) from $0-7 \cdot 5 \mathrm{~km}(\mathrm{O} / \mathrm{E}$ ratio $1.04 ; 95 \%$ confidence interval $(95 \%$ CI $)$ 1.02 to 1.06$)$ and 385 from $0-1 \mathrm{~km}(\mathrm{O} / \mathrm{E}$ $1 \cdot 10 ; 1 \cdot 00$ to $1 \cdot 22)$. There was an excess of skin melanoma from $0-1 \mathrm{~km}$ based on 11 cases $(\mathrm{O} / \mathrm{E} 2 \cdot 13 ; 1.06$ to $3 \cdot 80)$, and an excess from $0-7.5 \mathrm{~km}$ of cancer of the lung, stomach and pancreas combined, and prostate (O/Es ranged from 1.09 to 1.13). Only the findings from lung cancer were suggestive of a decline in risk with distance, especially in the later period (1982-9). There were 9196 cancer deaths (1981-92) from 0-7.5 km (O/E 1.04; 95\% CI 1.02 to 1.06$)$ and 308 from $0-1 \mathrm{~km}(O / E$ $1.24 ; 1.11$ to 1.39$)$; and 25507 non-cancer deaths $(O / E$ 1.02; 1.01 to 1.04$)$ from $0-7.5$ $\mathrm{km}$ and $745(\mathrm{O} / \mathrm{E} 1.14 ; 1.06$ to 1.22$)$ from $0-1 \mathrm{~km}$. There was evidence of a decline in mortality with distance for all cancers combined, lung cancer $(P=0.001$ for each), and colorectal cancer $(P<0.05)$, and also for non-cancers $(P=0.001)$. Proportional mortality analyses suggested a decline in risk with distance for lung cancer $(P=0.003)$ but not for all cancers or the site specific cancers examined. There was no evidence of an excess in the incidence or mortality from brain cancer. For cancer mortality in the innermost wards, the findings were, for the most part, well within the range of variation across the region as a whole.

Conclusions-The study provides limited and inconsistent evidence for a localised excess of cancer in the vicinity of the PBI plant. At present, further investigation does not seem warranted other than continued surveillance of mortality and cancer incidence in the locality.

(Occup Environ Med 1997;54:101-107)

Keywords: pesticides; fertilisers; cancer

On 7 January 1993 a Carlton Television documentary, Storyline, reported an apparent cluster of cancers in the vicinity of the Pan Britannica Industries (PBI) plant in Waltham Abbey ${ }^{1}$ which formulates a range of pesticides and fertilisers. The programme discussed the cases of several PBI employees and nearby residents who had developed or died of cancer over a 10 year period. The specific cancer sites included brain, colon, lung, pancreas, and melanoma of the skin. Although no causative agent or route of exposure was suggested, the PBI plant has handled possible human carcinogens and an informal analysis of cancer mortality carried out for the programme suggested that there had been more deaths than expected from national rates among the workforce and including three unconfirmed cases of brain cancer over 10 years among residents who lived in a road bordering the plant. The documentary therefore raised concerns but did not offer specific hypotheses.

This report gives the results of a formal epidemiological investigation undertaken by the Small Area Health Statistics Unit (SAHSU) ${ }^{23}$ into cancer incidence and mortality in the vicinity of the PBI plant.

\section{Methods}

The site of the study was the PBI plant in Waltham Abbey, Essex, EN9 1NP, located just outside the M25 motorway north east of London and east of the housing and industrial development along the Lea valley (fig 1). The population density in surrounding areas is highest to the south and west. Based on census information for 1981 enumeration districts, the Waltham Abbey area seems to be less socioeconomically deprived than the average for England and Wales as a whole, and there is little change in deprivation with distance from the plant.

The Ordnance Survey (OS) grid reference used for the factory site, 1538500 east, 1200300 north, is a node of an OS $100 \mathrm{~m}$ grid network lying within the boundary of the site 
Figure 1 Circles of 1 and $7.5 \mathrm{~km}$ around the $P B I$ plant, Waltham Abbey.

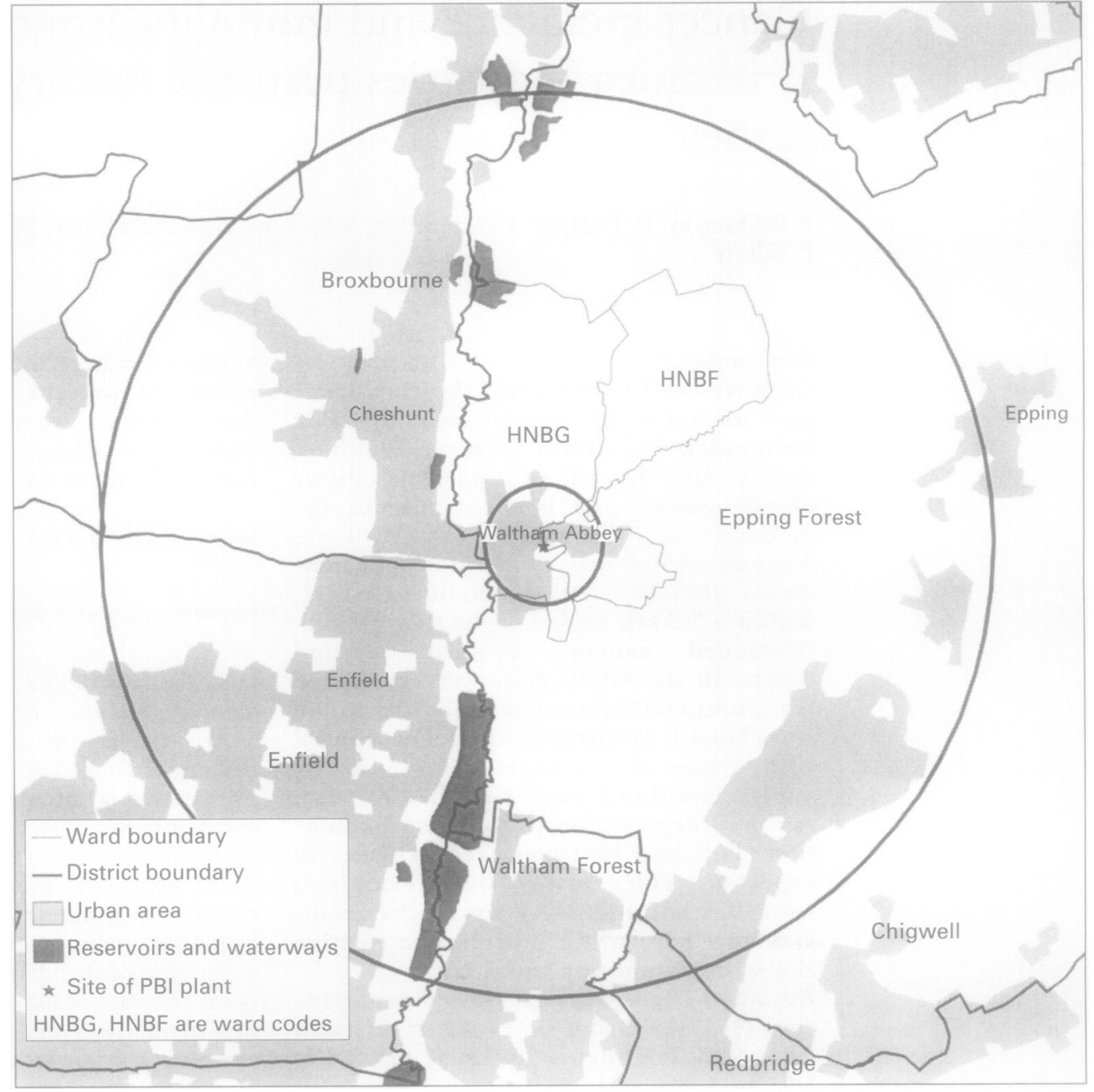

to the east of the A112 road. An area within 1 $\mathrm{km}$ of this point was chosen at the outset as having potentially the highest exposure to emissions from the plant. Over 250 chemical agents have been handled at the plant (list provided by the company) but there was no substantive evidence to suggest a putative agent or route of exposure. It was therefore assumed that exposure and risk were highest close to the plant and declined at some (unspecified) distance from it. The risk of cancer was examined in eight concentric bands up to $7.5 \mathrm{~km}$ from the site with outer limits at $1,2,3,4 \cdot 3$, $5 \cdot 3,6 \cdot 1,6 \cdot 8$, and $7 \cdot 5 \mathrm{~km}$.

Population counts by band were estimated from census small area statistics that used the 1981 census up to and including 1986, and the 1991 census thereafter. Expected (E) numbers of deaths or cancer registrations were calculated by year and band with England and Wales rates stratified by five-year age group, sex, and quintile of the enumeration district Carstairs deprivation index ${ }^{4}$ (1981 and 1991 censuses as appropriate). These were further adjusted for disease specific standardised regional registration ratios. ${ }^{5}$

Formal tests of hypotheses were based on the Stone's maximum likelihood ratio test. ${ }^{67}$ Both unconditional and conditional tests were performed. $^{89}$ The null hypothesis for the unconditional test, that the relative risk in each band is equal to one, is rejected if the relative risk is higher or lower than one over the study area as a whole or if it declines with distance. The conditional test is specifically for trend as it corrects for the overall level of risk by setting the condition that the sum of expected numbers over the $7.5 \mathrm{~km}$ area is equal to the sum of the observed (O) cases. Proportional mortality (PMR) analyses were also carried out with non-cancer deaths to obtain expected values. ${ }^{10}$

The following diagnostic groups of the 8th and 9 th revisions of the International Classification of Diseases (ICD-8 and ICD-9) were examined: (a) all cancers combined excluding non-melanoma cancer of the skin (140 to 208, excluding 173 and ICD-9 238.6); (b) brain tumours, malignant (191 and 192) and combined with benign and unspecified brain tumours $(191,192,225,237 \cdot 5,237 \cdot 6$, 237.9); (c) cancer of the trachea, bronchus, and lung (162); (d) pancreatic cancer alone (157) and combined with stomach (151); (e) melanoma of the skin (172).

Brain cancer was of particular interest because of the three unconfirmed cases reported in the original television documencancer site, age group (0-14, 15-64, and $\geqslant 65$ ), and sex. tary. Separate analyses were carried out by 
PERIODS OF STUDY

The periods of study were constrained by the availability and quality of postcoded data.

\section{Incidence}

The Small Area Health Statistics Unit cancer registration data covered the period 1974-89. The completeness of registration in North East Thames Region throughout this period is unknown, but a year by year comparison of the number of registrations in each census district within the region with the number expected from the rates for England and Wales indicated relative underreporting in several districts, including Enfield, Epping Forest, Waltham Forest, and Redbridge which contain or adjoin the PBI site (fig 1). Disparities were generally greatest for the years 1974-6, and it was decided at the outset to exclude these three years from the study, although this was an arbitrary cut off point. Hence, the analysis was confined to the years 1977-89. To include a period of investigation independent of the television documentary, the study period was divided into 1977-81 (the years before the time covered by the documentary) and 1982-9.

Mortality and proportional mortality ratios Mortality analyses (including proportional mortality) were carried out with data for 1981 to 1992 , as postcoded mortality data for earlier years are not available.

\section{CANCER MORTALITY IN THE NORTH EAST THAMES REGION}

A geographical analysis of variation of cancer mortality across the 601 electoral wards in the North East Thames Region was also carried out to help place in context the results for the study area. Variation in all cancers, lung cancer, and cancer of the stomach and pancreas combined was examined. Observed and expected cancer deaths (adjusted for age, sex, and deprivation) were computed with 1981-6 mortality data for 1981 wards, and 1987-91 data for 1991 wards. With a geographical information system, each 1991 ward was linked to the 1981 ward with the greatest overlap in area, so that their results could be combined. Empirical Bayesian methods ${ }^{11-13}$ were used to smooth ward $\mathrm{O} / \mathrm{E}$ ratios towards the overall mean to reduce the random component of variability in them due to small population sizes. Raw and smoothed $\mathrm{O} / \mathrm{E}$ ratios for the 601 wards were ranked to show the specific rankings of the two wards, HNBG and HNBF, which together contain $96 \%$ of the population within $1 \mathrm{~km}$ of the PBI plant (fig 1).

\section{Results}

Results are given here for all ages, both sexes combined. Age and sex specific results are available on request. Tables 1 and 2 show results for cancer incidence and tables 3 and 4 show mortality.

\section{CANCER INCIDENCE}

From 1977-89, there were 12859 cancers from $0-7.5 \mathrm{~km}(\mathrm{O} / \mathrm{E}$ ratio $1.04 ; 95 \%$ confidence interval (95\% CI) 1.02 to 1.06$)$ and 385 from $0-1 \mathrm{~km}(\mathrm{O} / \mathrm{E} 1 \cdot 10 ; 1.00$ to $1 \cdot 22$, table 1$)$. Both sexes and both the 15-64 and the $\geqslant 65$ age groups contributed to this overall excess (not shown). Examination of data over the eight bands (table 2), together with the combination of Stone's tests, did not indicate a decline in risk of all cancers with distance from the site $(P=0.001$ unconditional test, $P=$ 0.35 conditional test).

There was no evidence of an excess in the incidence of brain neoplasms (tables 1 and 2). Of the other site specific cancers studied, there was an excess of skin melanoma from $0-1 \mathrm{~km}$ based on 11 cases (O/E $2 \cdot 13 ; 1.06$ to 3.80 ), and an excess from $0-7.5 \mathrm{~km}$ for cancer of the lung, and stomach and pancreas combined, (O/Es ranging from 1.09 to $1 \cdot 13$ ). For lung

Table 1 Incidence: observed and expected ${ }^{\star}$ cancer registrations in the study area: all ages, both sexes

\begin{tabular}{|c|c|c|c|c|c|c|c|c|}
\hline \multirow[b]{2}{*}{ Cancer } & \multicolumn{3}{|c|}{0 to $1 \mathrm{~km}$} & \multicolumn{3}{|c|}{1 to $7 \cdot 5 \mathrm{~km}$} & \multicolumn{2}{|c|}{ Stone's tests P values } \\
\hline & $O$ & $E$ & $O / E(95 \% C I)$ & $O$ & $E$ & $O / E(95 \% C I)$ & Unconditional & Conditional \\
\hline \multicolumn{9}{|l|}{ 1977-89: } \\
\hline All cancers & 385 & $348 \cdot 7$ & $1.10(1.00$ to 1.22$)$ & 12859 & $12392 \cdot 0$ & $1.04(1.02$ to 1.06$)$ & 0.001 & 0.35 \\
\hline $\begin{array}{l}\text { Brain neoplasm } t \\
\text { Stomach and }\end{array}$ & 4 & $8 \cdot 4$ & $0.48(0.13$ to 1.22$)$ & 266 & $281 \cdot 7$ & $0.94(0.83$ to 1.06$)$ & $0 \cdot 74$ & 0.94 \\
\hline pancreatic & 32 & $31 \cdot 0$ & $1.03(0.70$ to 1.45$)$ & 1225 & $1126 \cdot 9$ & $1.09(1.03$ to 1.15$)$ & 0.04 & 0.74 \\
\hline Lung & 82 & $68 \cdot 0$ & $1.21(0.96$ to 1.50$)$ & 2792 & $2471 \cdot 5$ & $1.13(1.09$ to 1.17$)$ & 0.001 & 0.06 \\
\hline Skin melanoma & 11 & $5 \cdot 2$ & $2.13(1.06$ to 3.80$)$ & 189 & $168 \cdot 7$ & $1.12(0.97$ to 1.29$)$ & $0 \cdot 11$ & $0 \cdot 16$ \\
\hline Colorectal & 51 & $41 \cdot 8$ & $1.22(0.91$ to 1.60$)$ & 1560 & $1527 \cdot 5$ & $1.02(0.97$ to 1.07$)$ & $0 \cdot 14$ & $0 \cdot 10$ \\
\hline Prostate & 25 & $18 \cdot 3$ & $1.37(0.89$ to 2.02$)$ & 753 & $684 \cdot 7$ & $1.10(1.02$ to 1.18$)$ & 0.06 & 0.53 \\
\hline Breast (female) & 51 & $49 \cdot 3$ & $1.04(0.77$ to 1.36$)$ & 1695 & $1689 \cdot 7$ & $1.00(0.96$ to 1.05$)$ & 0.98 & 0.83 \\
\hline \multicolumn{9}{|l|}{ 1977-81: } \\
\hline All cancers & 117 & $116 \cdot 4$ & $1.00(0.83$ to 1.20$)$ & 4698 & $4253 \cdot 5$ & $1 \cdot 10(1.07$ to 1.14$)$ & 0.001 & 0.98 \\
\hline Brain neoplasm $t$ & 2 & 2.9 & $0.68(0.08$ to 2.47$)$ & 81 & $99 \cdot 7$ & $0.81(0.65$ to 1.01$)$ & 0.001 & 0.92 \\
\hline $\begin{array}{l}\text { Stomach and } \\
\text { pancreatic }\end{array}$ & 7 & $11 \cdot 0$ & $0.63(0.26$ to 1.31$)$ & 433 & $413 \cdot 2$ & $1.05(0.95$ to 1.15$)$ & 0.47 & $0 \cdot 87$ \\
\hline Lung & 20 & $24 \cdot 4$ & $0.82(0.50$ to 1.26$)$ & 1030 & 916.7 & $1.12(1.06$ to 1.19$)$ & 0.001 & 0.82 \\
\hline Skin melanoma & 3 & 1.4 & $2.22(0.46$ to 6.49$)$ & 69 & $45 \cdot 3$ & $1.52(1.19$ to 1.93$)$ & 0.01 & $0 \cdot 68$ \\
\hline \multicolumn{9}{|l|}{ 1982-9: } \\
\hline All cancers & 268 & $232 \cdot 3$ & $1.15(1.02$ to 1.30$)$ & 8161 & $8138 \cdot 4$ & $1.00(0.98$ to 1.02$)$ & $0 \cdot 1$ & 0.05 \\
\hline Brain neoplasm $†$ & 2 & $5 \cdot 5$ & $0.37(0.04$ to 1.32$)$ & 185 & $182 \cdot 0$ & $1.02(0.88$ to 1.17$)$ & $0 \cdot 88$ & 0.73 \\
\hline $\begin{array}{l}\text { Stomach and } \\
\text { pancreatic }\end{array}$ & 25 & $20 \cdot 1$ & $1.25(0.81$ to 1.84$)$ & 792 & $713 \cdot 7$ & $1.11(1.03$ to 1.19$)$ & 0.02 & $0 \cdot 38$ \\
\hline Lung & 62 & 43.6 & $1.42(1.09$ to 1.82$)$ & 1762 & $1554 \cdot 8$ & $1.13(1.08$ to 1.19$)$ & 0.001 & 0.01 \\
\hline Skin melanoma & 8 & $3 \cdot 8$ & $2.09(0.90$ to 4.12$)$ & 120 & $123 \cdot 4$ & $0.97(0.81$ to 1.16$)$ & 0.23 & $0 \cdot 13$ \\
\hline
\end{tabular}

«Expected cases adjusted for age, sex, socioeconomic deprivation, and regional standardised registration ratio.

†Malignant, benign, and unspecified tumours of the central nervous system. 
Table 2 Incidence of selected cancers by distance from the PBI plant, 1977-89: all ages, both sexes

\begin{tabular}{|c|c|c|c|c|c|c|c|c|c|c|c|c|}
\hline \multirow{2}{*}{$\begin{array}{l}\text { Outer radius } \\
\text { of band }(\mathrm{km})\end{array}$} & \multicolumn{2}{|c|}{ All cancers } & \multicolumn{2}{|c|}{ Brain neoplasms* } & \multicolumn{2}{|c|}{$\begin{array}{l}\text { Stomach and } \\
\text { pancreas }\end{array}$} & \multicolumn{2}{|l|}{ Lung } & \multicolumn{2}{|c|}{ Melanoma skin } & \multicolumn{2}{|c|}{ Prostate } \\
\hline & $O$ & $O / E t$ & $O$ & $O / E$ & $O$ & $O / E$ & $O$ & $O / E$ & $O$ & $O / E$ & $O$ & $O / E$ \\
\hline 1 & 385 & $1 \cdot 10$ & 4 & $0 \cdot 48$ & 32 & 1.03 & 82 & $1 \cdot 21$ & 11 & $2 \cdot 13$ & 25 & 1.37 \\
\hline 2 & 407 & 1.05 & 6 & 0.67 & 31 & 0.89 & 114 & $1 \cdot 40$ & 4 & 0.81 & 23 & 1.09 \\
\hline 3 & 992 & 1.02 & 23 & 0.97 & 102 & $1 \cdot 18$ & 240 & $1 \cdot 17$ & 11 & 0.85 & 51 & 0.98 \\
\hline $4 \cdot 3$ & 1677 & 1.03 & 35 & 0.89 & 164 & $1 \cdot 13$ & 380 & $1 \cdot 15$ & 24 & $1 \cdot 08$ & 75 & 0.88 \\
\hline $5 \cdot 3$ & 1415 & 0.95 & 39 & 1.09 & 148 & $1 \cdot 11$ & 335 & $1 \cdot 10$ & 25 & $1 \cdot 22$ & 53 & 0.67 \\
\hline $6 \cdot 1$ & 2104 & 1.09 & 38 & 0.86 & 179 & 1.02 & 424 & 1.15 & 33 & $1 \cdot 18$ & 143 & $1 \cdot 30$ \\
\hline $6 \cdot 8$ & 3088 & 1.06 & 62 & 0.99 & 303 & $1 \cdot 12$ & 618 & 1.06 & 41 & 1.07 & 204 & 1.25 \\
\hline $7 \cdot 5$ & 2791 & $1 \cdot 02$ & 59 & 1.01 & 266 & 1.06 & 599 & $1 \cdot 13$ & 40 & 1.09 & 179 & 1.15 \\
\hline \multicolumn{13}{|c|}{ Stone's tests $P$ values: } \\
\hline Unconditional & & 0.001 & & 0.74 & & $0 \cdot 04$ & & 0.001 & & $0 \cdot 11$ & & $0 \cdot 06$ \\
\hline Conditional & & 0.35 & & 0.94 & & $0 \cdot 74$ & & 0.06 & & $0 \cdot 16$ & & 0.53 \\
\hline
\end{tabular}

^Malignant, benign, and unspecified tumours of the central nervous system.

fObserved/expected ratio adjusted for age, sex, socioeconomic deprivation, and regional standardised registration ratio.

Table 3 Mortality: observed and expected ${ }^{\star}$ cancer and non-cancer deaths in the study area: all ages, both sexes

\begin{tabular}{|c|c|c|c|c|c|c|c|c|}
\hline \multirow[b]{2}{*}{ Cause } & \multicolumn{3}{|c|}{0 to $1 \mathrm{~km}$} & \multicolumn{3}{|c|}{1 to $7.5 \mathrm{~km}$} & \multicolumn{2}{|c|}{ Stone's tests P values } \\
\hline & $O$ & $E$ & $O / E(95 \% C I)$ & $O$ & $E$ & $O / E(95 \% C I)$ & Unconditional & Conditional \\
\hline All cancers & 308 & $247 \cdot 7$ & $1.24(1.11$ to 1.39$)$ & 9196 & $8872 \cdot 3$ & $1.04(1.02$ to 1.06$)$ & 0.001 & 0.001 \\
\hline Brain neoplasm & 3 & $6 \cdot 2$ & $0.48(0.10$ to 1.41$)$ & 200 & $205 \cdot 6$ & $0.97(0.84$ to 1.12$)$ & 0.93 & 0.86 \\
\hline Stomach and pancreatic & 27 & $26 \cdot 9$ & $1.01(0.66$ to 1.46$)$ & 1038 & $970 \cdot 2$ & $1.07(1.01$ to 1.14$)$ & $0 \cdot 21$ & $0 \cdot 84$ \\
\hline Lung & 88 & $60 \cdot 1$ & $1.46(1.17$ to 1.80$)$ & 2383 & $2168 \cdot 9$ & $1.10(1.06$ to 1.14$)$ & 0.001 & 0.001 \\
\hline Skin melanoma & 5 & $2 \cdot 2$ & $2.23(0.72$ to 5.20$)$ & 95 & $75 \cdot 2$ & $1.26(1.02$ to 1.54$)$ & 0.09 & $0 \cdot 38$ \\
\hline Colorectal & 39 & $27 \cdot \overline{9}$ & $1.40(1.00$ to 1.91$)$ & 1053 & $1019 \cdot 0$ & $1.03(0.97$ to 1.10$)$ & 0.05 & 0.03 \\
\hline Prostate & 19 & $12 \cdot 6$ & $1.51(0.91$ to 2.36$)$ & 500 & $465 \cdot 5$ & $1.07(0.98$ to 1.17$)$ & $0 \cdot 02$ & $0 \cdot 26$ \\
\hline Breast (female) & 30 & $26 \cdot 8$ & $1.12(0.76$ to 1.60$)$ & 943 & $940 \cdot 2$ & $1.00(0.94$ to 1.07$)$ & 0.71 & $0 \cdot 49$ \\
\hline Non-cancer & 745 & $656 \cdot 1$ & $1.14(1.06$ to 1.22$)$ & 25507 & $24936 \cdot 2$ & $1.02(1.01$ to 1.04$)$ & 0.001 & 0.001 \\
\hline
\end{tabular}

^Expected cases adjusted for age, sex, socioeconomic deprivation, and regional standardised registration ratio.

†Malignant, benign, and unspecified tumours of the central nervous system.

Table 4 Mortality from selected cancers by distance from the PBI plant, 1981-92: all ages, both sexes

\begin{tabular}{|c|c|c|c|c|c|c|c|c|c|c|c|c|c|c|c|c|c|c|c|c|}
\hline \multirow{2}{*}{$\begin{array}{l}\text { Outer radius of } \\
\text { band }(\mathrm{km})\end{array}$} & \multicolumn{3}{|c|}{ All cancers } & \multicolumn{3}{|c|}{ Brain neoplasms * } & \multicolumn{3}{|c|}{ Stomach and pancreas } & \multicolumn{3}{|c|}{ Lung } & \multicolumn{3}{|c|}{ Melanoma skin } & \multicolumn{2}{|c|}{ Colorectal } & \multirow[b]{2}{*}{$P M R$} & \multicolumn{2}{|c|}{ Non-cancers } \\
\hline & $O$ & $O / E t$ & $P M R$ & $O$ & $O / E$ & $P M R$ & $O$ & $O / E$ & $P M R$ & $O$ & $O / E$ & $P M R$ & $O$ & $O / E$ & $P M R$ & $O$ & $O / E$ & & $O$ & $O / E$ \\
\hline 1 & 308 & 1.24 & 1.08 & 3 & $0 \cdot 48$ & 0.44 & 27 & 1.01 & 0.83 & 88 & 1.46 & $1 \cdot 18$ & 5 & $2 \cdot 23$ & 1.55 & 39 & 1.40 & $1 \cdot 20$ & 745 & $1 \cdot 14$ \\
\hline 2 & 322 & $1 \cdot 18$ & 1.02 & 5 & $0 \cdot 81$ & $0 \cdot 70$ & 34 & $1 \cdot 14$ & 0.98 & 104 & $1 \cdot 46$ & 1.32 & 1 & 0.45 & $0 \cdot 28$ & 32 & 1.05 & 0.91 & 785 & 1.07 \\
\hline 3 & 717 & 1.04 & 1.00 & 15 & 0.92 & 0.87 & 83 & $1 \cdot 11$ & 1.03 & 212 & $1 \cdot 16$ & $1 \cdot 10$ & 9 & 1.58 & 1.15 & 75 & 0.99 & 0.95 & 1846 & 1.00 \\
\hline $4 \cdot 3$ & 1200 & 1.05 & 0.97 & 30 & $1 \cdot 11$ & 1.07 & 128 & 1.03 & 0.93 & 301 & 1.04 & 0.94 & 13 & 1.34 & 1.01 & 159 & 1.24 & $1 \cdot 15$ & 3319 & 1.05 \\
\hline $5 \cdot 3$ & 1033 & 0.99 & 0.99 & 23 & 0.92 & 0.93 & 122 & 1.07 & 1.05 & 302 & $1 \cdot 14$ & $1 \cdot 10$ & 10 & $1 \cdot 12$ & 0.87 & 89 & $0 \cdot 76$ & 0.76 & 2699 & 0.95 \\
\hline $6 \cdot 1$ & 1431 & 1.03 & 1.01 & 27 & 0.82 & 0.91 & 146 & 0.97 & 0.89 & 348 & 1.08 & 0.96 & 18 & 1.45 & 1.25 & 179 & $1 \cdot 10$ & 1.07 & 4253 & 1.07 \\
\hline $6 \cdot 8$ & 2150 & 1.03 & 1.00 & 54 & $1 \cdot 15$ & 1.22 & 261 & $1 \cdot 14$ & 1.07 & 508 & 1.01 & 0.91 & 20 & $1 \cdot 16$ & 0.92 & 228 & 0.94 & 0.91 & 6099 & 1.02 \\
\hline \multicolumn{21}{|l|}{$\begin{array}{l}\text { Stone's tests } \\
\text { P values: }\end{array}$} \\
\hline Unconditional & & 0.001 & & & 0.93 & & & $0 \cdot 21$ & & & 0.001 & & & 0.09 & & & 0.05 & & & 0.001 \\
\hline Conditional & & 0.001 & $0 \cdot 33$ & & $0 \cdot 86$ & 0.92 & & $0 \cdot 84$ & 0.95 & & 0.001 & 0.003 & & $0 \cdot 38$ & 0.52 & & 0.03 & $0 \cdot 30$ & & 0.001 \\
\hline
\end{tabular}

^Malignant, benign, and unspecified tumours of the central nervous system.

†Observed/expected ratio adjusted for age, sex, socioeconomic deprivation, and regional standardised registration ratio.

cancer there was some evidence of a decline in risk with distance $(\mathrm{P}=0.001$ unconditional test, $\mathrm{P}=0.06$ conditional test, tables 1 and $2)$, especially in the later period, 1982-9 ( $\mathrm{P}=$ 0.001 and $\mathrm{P}=0.01$ ), when a $42 \%$ excess from $0-1 \mathrm{~km}$ was found based on 62 cases $(\mathrm{O} / \mathrm{E} 1.42 ; 1.09$ to 1.82 , table 1$)$.

Because of the overall excess in all cancers, the incidence (and mortality) of three additional common cancers were examined for descriptive purposes from 1977-89: colorectal cancer (ICD 153-154); prostatic cancer (ICD 185); and cancer of the female breast (ICD 174). There was an excess of prostate cancer from $0-7.5 \mathrm{~km}(\mathrm{O} / \mathrm{E} 1.10 ; 1.02$ to 1.18$)$; the combination of Stone's tests was not indicative of decline in risk with distance $(P=0.06$ unconditional; $\mathrm{P}=0.53$ conditional, table 1 ).

\section{MORTALITY}

From 1981-92, there were 9196 cancer deaths from $0-7.5 \mathrm{~km}(\mathrm{O} / \mathrm{E} 1.04 ; 1.02$ to 1.06$)$ and 308 from $0-1 \mathrm{~km}(\mathrm{O} / \mathrm{E} 1 \cdot 24 ; 1.11$ to 1.39 , table 3). Within $1 \mathrm{~km}$ cancers of the lung $(\mathrm{O} / \mathrm{E}$ $1.46 ; 1.17$ to 1.80 ), colon and rectum, prostate, and breast, as well as melanoma of the skin, contributed to the excess in mortality from all cancers. As with cancer incidence, the overall excess was apparent for both sexes, and for the 15-64 and $\geqslant 65$ age groups (not shown). From $0-7 \cdot 5 \mathrm{~km}$ there was an excess of stomach and pancreatic cancer combined, lung cancer, and skin melanoma $(\mathrm{O} / \mathrm{Es}$ ranging from 1.07-1 26). There was evidence of a decline in mortality with distance for all cancers, lung cancer $(P=0.001$, unconditional and conditional Stone's tests for both), and colorectal cancer $(P=0.05$ and 0.03 , tables 3 and 4$)$. There was also excess non-cancer mortality within $1 \mathrm{~km}$ of the site $(\mathrm{O} / \mathrm{E}$ ratio $1.14 ; 1.06$ to 1.22$)$ and over $0-7.5 \mathrm{~km}(\mathrm{O} / \mathrm{E}$ $1.02 ; 1.01$ to 1.04$)$ with a significant decline with distance $(P=0.001$, unconditional and conditional Stone's tests, tables 3 and 4).

Table 4 also shows the results of the proportional mortality analyses. Only one Stone's 


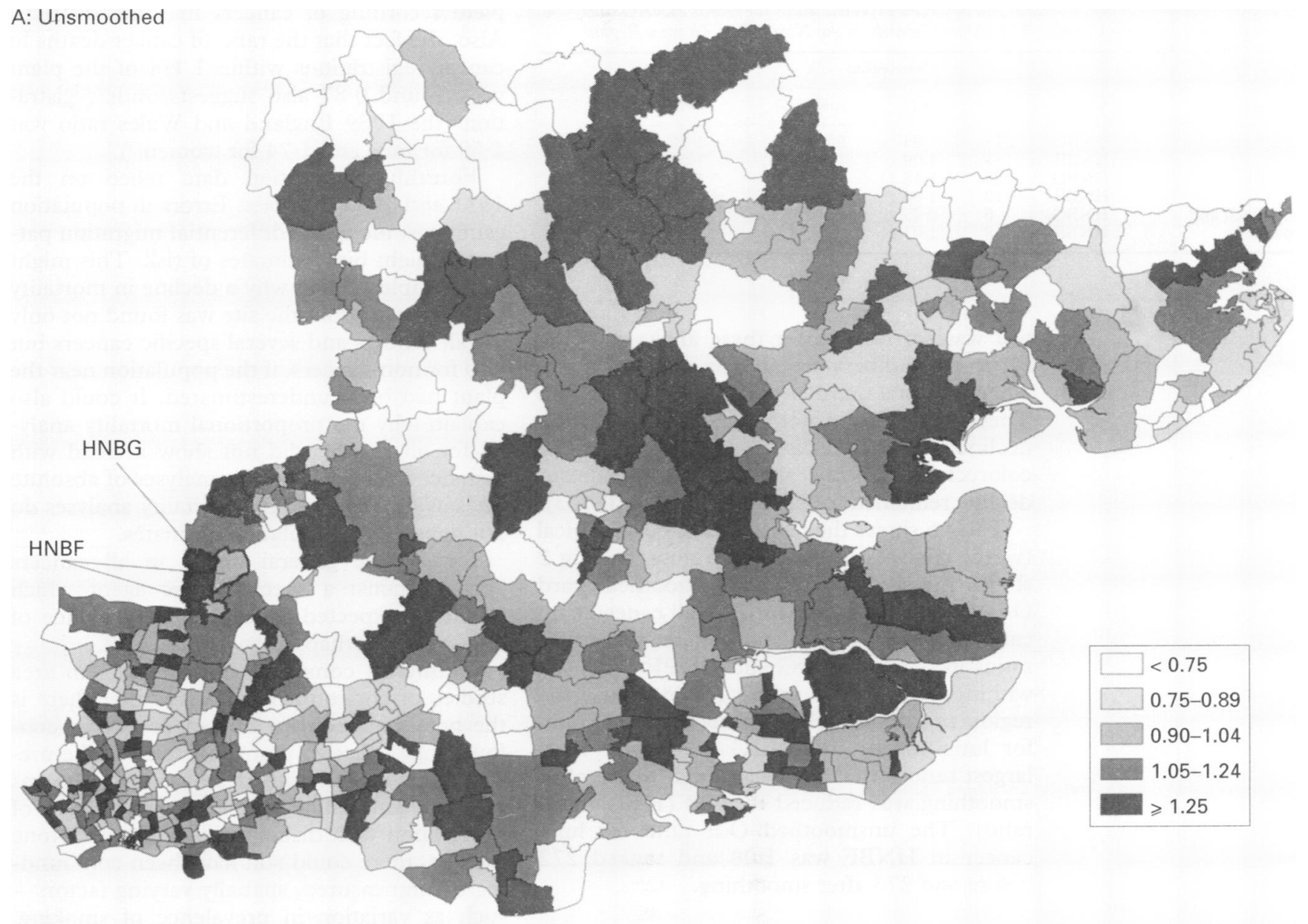

B: Smoothed

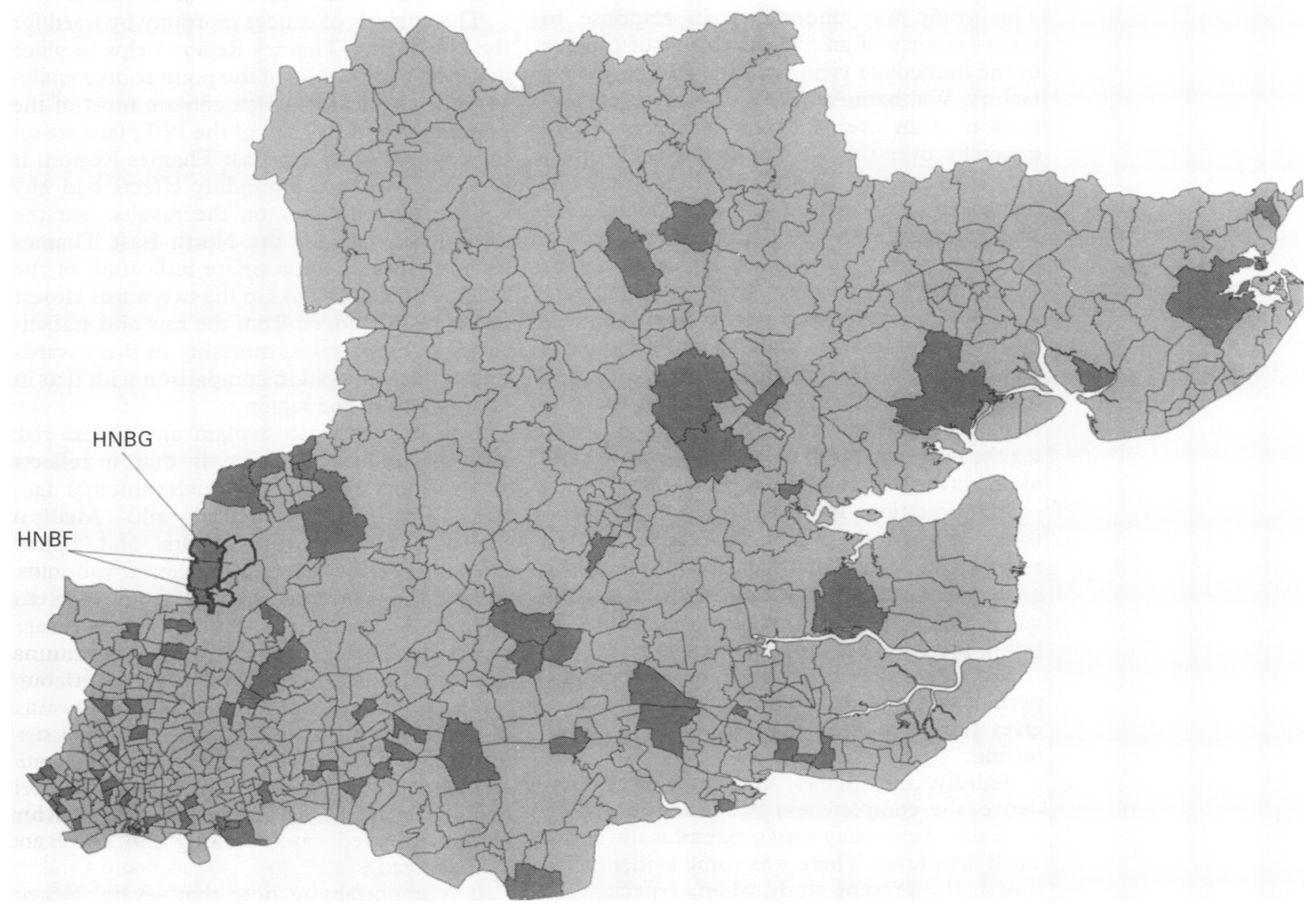

Figure 2 Ward maps adjusted for age, sex and deprivation of O/E ratios for lung cancer mortality in the North East Thames Region, $1981-92$. 
Table 5 Observed cancer deaths and observedlexpected ratios for wards HNBG and $H N B F$ and their ranks among 601 electoral wards in the North East Thames Region

\begin{tabular}{|c|c|c|c|c|c|c|}
\hline \multirow[b]{2}{*}{ Cancer site } & \multirow[b]{2}{*}{ Ward } & \multirow[b]{2}{*}{$O$} & \multicolumn{2}{|c|}{ Unsmoothed } & \multicolumn{2}{|c|}{ Smoothed } \\
\hline & & & $O / E$ & $\operatorname{rank}(\%)$ & $O / E$ & rank (\%) \\
\hline \multirow[t]{2}{*}{ All cancers } & HNBG & 255 & 1.03 & $220(36 \cdot 6)$ & 1.02 & $208(34 \cdot 6)$ \\
\hline & HNBF & 184 & 1.09 & $123(20 \cdot 5)$ & 1.03 & $121(20 \cdot 1)$ \\
\hline \multirow[t]{2}{*}{ Lung } & HNBG & 28 & 1.48 & $42(7 \cdot 0)$ & 1.08 & $16(2 \cdot 7)$ \\
\hline & HNBF & 12 & 1.00 & $272(45 \cdot 3)$ & 1.00 & $273(45 \cdot 4)$ \\
\hline \multirow{2}{*}{$\begin{array}{l}\text { Stomach and } \\
\text { pancreas }\end{array}$} & HNBG & 6 & 0.45 & $562(93.5)$ & 0.93 & $594(98 \cdot 8)$ \\
\hline & $\mathrm{HNBF}$ & 8 & 1.03 & $272(45 \cdot 3)$ & 1.00 & $274(45 \cdot 6)$ \\
\hline
\end{tabular}

test was carried out for these analyses as the expected numbers are already constrained to equal the total number of cases within $7 \cdot 5 \mathrm{~km}$. These analyses did not suggest evidence of a decline in risk with distance for all cancers or colorectal cancers, although a significant decline remained for lung cancer $(P=0.003)$.

Table 5 shows the results of the geographical (ward) analyses of cancer mortality, and fig 2 shows the unsmoothed and smoothed ward $\mathrm{O} / \mathrm{E}$ ratios for lung cancer. For all cancers and cancer of the stomach and pancreas, the $\mathrm{O} / \mathrm{E}$ ratios for wards $\mathrm{HNBG}$ and $\mathrm{HNBF}$ were well within the range of values found across the region as a whole. The unsmoothed $\mathrm{O} / \mathrm{E}$ ratio for lung cancer in HNBG was 1.48 (42nd largest ratio out of the 601 wards) which after smoothing was reduced to 1.08 (16th largest ratio). The unsmoothed $\mathrm{O} / \mathrm{E}$ ratio for lung cancer in $\mathrm{HNBF}$ was 1.00 and ranked 272 before and 273 after smoothing.

\section{Discussion}

This study was undertaken in response to media reports of an alleged cluster of cancers in the immediate vicinity of the PBI pesticides factory, Waltham Abbey. We found some suggestion of an overall excess of cancers more generally over the $7.5 \mathrm{~km}$ radius study area, but inconsistent evidence for a trend of decreasing risk with distance. Evidence for this, strongest for lung cancer, was apparent in the later period for cancer incidence (from 1982) and for mortality (from 1981). There was also an unexplained excess of non-cancer mortality within $1 \mathrm{~km}$ and $7.5 \mathrm{~km}$ of the plant with evidence of a decline in risk with distance. Results of cancer mortality in the two electoral wards around the factory site were, for the most part, well within the range of variation across the region as a whole.

Interpretation is complicated by several issues. Firstly, the study was carried out in response to reports of an alleged cluster at the same site. Under these circumstances, statistical testing is formally invalid as $P$ values do not properly reflect the play of chance.

Secondly, the multiplicity of end points, periods etc, not all of which are independent, gives rise to additional problems of multiple testing.

Thirdly, the quality, and for cancer incidence, the completeness of routine recording of health events may vary geographically at the small area level. There was some evidence for this in the present study when, especially in the earlier years, there was apparent incom- plete recording of cancers in some districts. Also, the fact that the ratio of cancer deaths to cancer registrations within $1 \mathrm{~km}$ of the plant was around 0.87 also suggests underregistration (the 1989 England and Wales ratio was 1.59 for men and 1.74 for women ${ }^{14}$ ).

Fourthly, population data relied on the 1981 and 1991 censuses. Errors in population estimates, including differential migration patterns, might bias estimates of risk. This might for example explain why a decline in mortality with distance from the site was found not only for all cancers and several specific cancers but also for non-cancers, if the population near the plant had been underestimated. It could also explain why the proportional mortality analysis for all cancers did not show a trend with distance in contrast to the analyses of absolute rates as the proportional mortality analyses do not depend on population estimates.

Fifthly, the general excess in all cancers argues against a specific toxic agent which might be expected to affect the incidence of only one or perhaps a few cancer sites.

Sixthly, in common with other small area studies of environment and health, ${ }^{58}$ there is the potential problem of socioeconomic confounding, although perhaps less so in the present study because the area near the plant was relatively affluent, with little change in levels of deprivation with distance from the site. None the less, there could still have been confounding by unmeasured, spatially varying factorssuch as variation in prevalence of smoking. Routine sources of data on smoking patterns at the local (small area) level do not exist.

The analysis of cancer mortality by ward for the North East Thames Region helps to place in context the results of the point source analysis. The two wards which contain most of the population within $1 \mathrm{~km}$ of the PBI plant are on the edge of the North East Thames Region. It is unclear whether boundary effects had any appreciable influence on the results, but the analysis of data for the North East Thames Region gives an appropriate indication of the ranking of relative risks in the two wards closest to the plant. Judged from the raw and statistically smoothed rates, mortality in these wards was not exceptional in comparison with that in other wards in the region.

One possibility to explain any excess risk near an industrial source is that it reflects occupational rather than environmental factors. The Epidemiological and Medical Statistics Unit of the Health and Safety Executive (HSE) has studied cancer mortality among the workforce at PBI from 1978 to 1992.15 Altogether 13 cancer deaths were reported. This compares with 308 cancer deaths reported here from 1981-92 among residents within $1 \mathrm{~km}$ of the plant. The results of the HSE study showed a small (but not significant) excess of all cancers among men employed for at least one year on the PBI site, mainly reflecting an excess of lung cancer (seven observed cases of lung cancer versus $2 \cdot 5$ expected).

It is important to note that several industries have been located near the PBI plant, 
including some that have now closed. The company was established on the site of a former explosives factory, and less than $1 \mathrm{~km}$ to the north west and the south west lie two sites of the former Ministry of Defence Explosives Research and Development Establishment, which contain land reported to be contaminated with asbestos and other substances (D Perry, personal communication).

In summary, within the limitations of the small area approach and use of routine data the study provides limited and inconsistent evidence for a localised excess of cancer in the vicinity of the PBI plant. Although there was a small general increase in risk over the wider $7.5 \mathrm{~km}$ study area, and a decline in incidence of lung cancer and mortality with distance from the plant, increased risk and decline in risk with distance were also found for noncancer mortality, which argues against a specific cancer hazard. For cancer mortality in the innermost wards, the findings were, for the most part, well within the range of variation across the region as a whole. At present, further investigation of this alleged cluster does not seem to be warranted, although surveillance of mortality and cancer incidence in the locality as a whole would indicate whether or not the apparent excess risk of disease persists.

The Small Area Health Statistics Unit is funded by grants from the Department of Health, Department of the Environment, Health and Safety Executive, Scottish Office Home and Health Department, Welsh Office, and Northern Ireland Department of Health and Social Services. We thank the Census, Population and Health Group of the Office of National Statistics (formerly Office of Population Censuses and Surveys) Statistics (formerly Office of Population Censuses and Surveys)
who made postcoded data available to us and provided copies of death certificates. We are grateful to the Thames Cance Registry for checking registration details of individual cases; to Dr David Perry (HMPIF) who provided information about local industries; and to Dr J Osman and Mrs S Hutchings of the HSE's Epidemiological and Medical Statistics Unit for discussing with us the findings of their study of the workforce.
The views expressed in this paper are those of the authors and not necessarily those of the funding departments.

1 Carlton Television. Storyline report: a growing concern Broadcast on 7 January 1993.

2 Elliott P, Kleinschmidt I, Westlake AJ. The use of routine data in studies of point sources of environmental pollution. In: Elliott P, Cuzick J, English D, Stern R, eds. tion. In: Elliott P, Cuzick J, English D, Stern R, eds.
Geographical and environmental epidemiology: methods for Geographical and environmental epidemiology: methods for
small-area studies. Oxford: Oxford University Press, 1992; 10:106-14.

3 Elliott P, Westlake AJ, Hills M, Kleinschmidt I, Rodrigues L, McGale P, et al. The Small Area Health Statistics Unit: a national facility for investigating health around point sources of environmental pollution in the United Kingdom. $f$ Epidemiol Community Health 1992;46: 345-9.

4 Carstairs V, Morris R. Deprivation and health in Scotland. Aberdeen: Aberdeen University Press, 1991.

5 Elliott $P$, Shaddick G, Kleinschmidt I, Jolley D, Walls P, Beresford J, Grundy C. Cancer incidence near municipal solid waste incinerators in Great Britain. Br f Cancer 1996;73:702-10.

6 Stone RA. Investigations of excess environmental risks around putative sources: statistical problems and a proposed test. Stat Med 1988;7:649-60.

7 Hills $M$. Some comments on methods for investigating disease risk around a point source. In: Elliott $P$, Cuzick J English D, Stern R, eds. Geographical and environmental epidemiology: methods for small-area studies. Oxford Oxford University Press, 1992;20:231-7.

8 Sans S, Elliott P, Kleinschmidt I, Shaddick G, Pattenden $\mathrm{S}$, Walls $\mathrm{P}$, et al. Cancer incidence and mortality near the Baglan Bay petrochemical works, South Wales. Occup Environ Med 1995;52:217-24.

9 Bithell JF. The choice of test for detecting raised disease risk near a point source. Stat Med 1995;14:2309-22.

10 Breslow NE, Day NE. Statistical methods in cancer research. Volume II. The design and analysis of cohort studies. Lyon: International Agency for Research on Cancer, 1987;2 76-9.

11 Elliott P, Martuzzi M, Shaddick G. Spatial statistical methods in environmental epidemiology: a critique. Stat Methods Med Res 1995;4:139-61.

12 Clayton D, Bernardinelli L. Bayesian methods for mapping disease risk. In: Elliott P, Cuzick J, English D, Stern R, eds. Geographical and environmental epidemiology. Methods for small-area studies. Oxford: Oxford University Press, 1992:205-20

13 Clayton D, Kaldor J. Empirical Bayes estimates of agestandardized relative risks for use in disease mapping. standardized relative risks
Biometrics $1987 ; 43: 671-81$.

14 Office of Population Censuses and Surveys. Cancer statistics. Registrations of cancers diagnosed in 1989, England and Wales. London: HMSO, 1994. (Series MB1 No 22.)

15 Health and Safety Executive. Pan Britannica Industries, Waltham Abbey. Studies of cancer in the workforce. London: HSE, 1995

\section{Rejected manuscripts}

From February 1994, authors whose submitted articles are rejected will be advised of the decision and one copy of the article, together with any reviewers' comments, will be returned to them. The fournal will destroy remaining copies of the article but correspondence and reviewers' comments will be kept. 


\section{CORRESPONDENCE}

Cancer mortality among workers in the German rubber industry

The large scale study of cancer mortality among workers in the German rubber industry by Weiland et al, ${ }^{1}$ is a well conducted and professional cohort study, which seems to have indicated the need for research in this industrial field.

Knowing the difficulties of carrying out such studies in Germany the authors have to be congratulated for achieving this result. However, one finding requires discussion. A possible reason why two incident cases of a laryngeal cancer were found in the same cohort in 1982-without contributing to mortality-could be explained because there is a putative cause involved, as it was known that the exposure was to the highest concentrations of nitrosamines ever found at a workplace according to the publication by the Department of Analytical Toxicology of the German Cancer Research Center. ${ }^{2}$

The measurements were reported to the public but were not in the analysis of the study of Weiland et al. These findings may therefore reflect an independent and specific indicator of a particular hazard, and the history of the sponsorship of this study is directly related to the findings of the two cases of laryngeal cancer requiring compensation as an occupational disease. $A$ further analysis of the data of the study by Weiland et al with an analysis by stratification according to worksites could perhaps identify the specific risk situation better than, or at least as well as, the year of hire or observation period (years since hire) which contrasted with the data on the cancers of upper respiratory airways. The findings so far are inconsistent although indicative of plausible specific risks, so that a detailed analysis is warranted.

$$
\begin{array}{r}
\text { R FRENTZEL-BEYME } \\
\text { Medicine (BIPS), } \\
\text { Bremen Institute for Prevention Research and Social } \\
\text { Postfach 10 6767, 28067 Bremen, } \\
\text { Germany } \\
\text { Weiland KW, Mundt KA, Keil U, Kraemer B, } \\
\text { Birk T, Person M, et al. Cancer mortality } \\
\text { among workers in the German rubber indus- } \\
\text { try: 1981-91. Occup Environ Med 1996;53: } \\
\text { 289-98. } \\
2 \text { Spiegelhalder B, Preussmann R. Occupational } \\
\text { nitrosamine exposure. 1. Rubber and tyre } \\
\text { industry. Carcinogenesis 1983;4:1147-52. }
\end{array}
$$

Authors' reply-We thank Frentzel-Beyme for his interest in our paper. The purpose of our report ${ }^{1}$ was to present the total and cause specific mortality of production workers in the German rubber industry, and to examine the cancer mortality by year of hire and years since hire. As we point out in the introduction to our article, the reason we conducted the study was the concern not only about a possible increase in the morbidity and mortality from laryngeal cancers, but also from cancers of other sites. ${ }^{23} \mathrm{We}$ had therefore decided to conduct a historical cohort study to investigate the mortality of rubber workers in comparison with the general population of West Germany. The cohort approach has the advantage that it allows the description of the mortality from many causes. Our findings of an increased mortality from several cancers, including cancer of the pleura and lung as well as from leukaemia, show the value of this research strategy. Dye to the lack of population based cancer registries in Germany, a cancer incidence study would not have been feasible.

A mortality study, however, has limitations for the study of cancers which have relatively low fatality-for example, laryngeal cancer. Firstly, there is a loss of statistical power due to fewer deaths from laryngeal cancer than incident cases. Secondly, the standardised mortality ratio (SMR) may not give a good estimate of the standardised incidence ratio (SIR) if, for example, fatality is related to exposure, or if rapid changes in the incidence have occurred which were not yet reflected in the mortalities. Although we have no evidence that this may have been the case and, for the other reasons discussed in our paper, it is prudent to interpret the findings on mortality from laryngeal cancer with due caution.

The next step in the analyses of our data is to investigate the effect of occupational exposures in more detail. As we state in our paper, we are currently conducting further analyses of the work history data to find whether any of the observed excesses of cancers are related to work areas and specific exposures. A manuscript presenting the cancer mortality by exposure in specific work areas will soon be submitted for publication.

Furthermore, in collaboration with experts, including Spiegelhalder, we are developing an exposure matrix to investigate the effect of specific exposure, with special emphasis on established respiratory carcinogens and nitrosamines. Available nitrosamine measurements from the early 1980 s will be taken into account, ${ }^{4}$ but need to be evaluated carefully because the measurement was not based on epidemiological principles. These analyses will be presented in due course.

STEPHAN K WEILAND KENNETH A MUNDT KURT STRAIF Institute of Epidemiology and Social $\Lambda$ and Social Medicine, University of Münster, KENNETH A MUNDT

Department of Biostatistics and Epidemiology, School of Public Health and Health Sciences, University of Massachusetts, Amherst, Massachusetts, USA

1 Weiland SK, Mundt KA, Keil U, Kraemer B, Birk T, Person M, et al. Cancer mortality among workers in the German rubber industry: 1981-91. Occup Environ Med 1996;53: 289-98.

2 International Agency for Research on Cancer. LARC monographs on the evaluation of carcinogenic risk of chemicals to humans. The rubber industry. Vol 28. Lyon: IARC, 1982.

3 International Agency for Research on Cancer. LARC monographs on the evaluation of carcinogenic risk of chemicals to humans. Overall evalgenic risk of chemicals to humans. Overall evaluations of carcinogenicity: an updating of IARC
monographs. Vols 1-42 (suppl 7). Lyon: monographs.

4 Spiegelhalder B, Preussmann R. Occupational nitrosamine exposure. 1. Rubber and tyre industry. Carcinogenesis 1983;4:1147-52.

\section{NOTICES}

The third international conference on occupational health for health care workers. 29 June-2 July 1997. Edinburgh, Scotland.

The conference is being organised on behalf of the International Commission on
Occupational Health and its Scientific Committee on Occupational Health for Health Care Workers by representatives of the professional bodies in the United Kingdom involved in this field. It will be of interest to a wide multi-disciplinary audience.

The occupational health of health care workers is assuming increasing importance, not only due to the wide range of hazards affecting this group within the healthcare environment, but also because of potential impact on the health of patients and the wider environment. Our conference themeenvironmental interactions-will help to focus attention on all these dimensions. Our aim is to create a participative conference in which there will be effective interchange among all the delegates through keynote addresses, workshops, discussion sessions, and posters. These will also be linked with an enjoyable social programme which will encourage you to experience a flavour of Scottish life and culture.

Further information from: Ted McGuire, Conference Bureau, 17 Hillpark Terrace, Edinburgh. Scotland EH4 7SX. United Kingdom. Telephone: +44 1313128435 ; Fax: +44131312 8435 .

The 4th Congress of the European Society of Contact Dermatitis (ESCD) 9-11 July 1998. Marina Congress Center, Heloinid, Finland

The organisers, the European Society of Contract Dermatitis, the Finnish Contact Dermatitis Group, and the Finnish Society of Dermatology, cordially welcome you to the 4th meeting of the ESCD in Helsinki, Finland, in 1988 .

The meeting will cover every aspect of contact dermatitis, including allergic and irritant contact dermatitis, occupational and environmental dermatitis, cutaneous toxicology, and dermatitis from cosmetics, with invited lectures, free communications, posters, and workshops on epidemiology, pathomechanism, diagnostics, prevention, and treatment of contact dermatitis. Also a trade exhibition will be held during the meeting. For further information, please contact: ESCD-98 Secretariat, Ms Kirsi Saarelma, Congress Manager, Limingantie 8, FIN-00550 Helsinki, Finland tel + 3589 790080, fax +35897573630 .

\section{CORRECTION}

Cancer incidence and mortality around the PBI pesticide factory, Waltham Abbey (1997;54:101-7).

The second distance heading in tables 1 and 3 should read $0-7.5 \mathrm{~km}$ and not $1-7.5 \mathrm{~km}$.

The first full sentence of the second column of page 106 should read: Also the fact that the ratio of cancer registrations to cancer deaths within $1 \mathrm{~km}$ of the plant was around $1 \cdot 15$ suggests underregistration (the 1989 England and Wales ratio was 1.59 for men and 1.74 for women). 